\title{
Glaciological settings and recent mass balance of Blåskimen Island in Dronning Maud Land, Antarctica
}

\author{
Vikram Goel $^{1}$, Joel Brown ${ }^{1,2}$, and Kenichi Matsuoka ${ }^{1}$ \\ ${ }^{1}$ Norwegian Polar Institute, Troms $\emptyset$, Norway \\ ${ }^{2}$ Aesir Consulting LLC, Missoula, Montana, USA \\ Correspondence: Vikram Goel (vikram.goel@outlook.com)
}

Received: 10 April 2017 - Discussion started: 29 May 2017

Revised: 4 October 2017 - Accepted: 9 October 2017 - Published: 12 December 2017

\begin{abstract}
The ice-shelf-fringed coast of Dronning Maud Land in East Antarctica contains numerous ice rises that influence the dynamics and mass balance of the region. However, only a few of these ice rises have been investigated in detail. Here, we present field measurements of Blåskimen Island, an isle-type ice rise adjacent to Fimbul Ice Shelf. This ice rise is largely dome shaped, with a pronounced ridge extending to the south-west from its summit ( $410 \mathrm{~m}$ a.s.l.). Its bed is mostly flat and about $100 \mathrm{~m}$ below the current sea level. Shallow radar-detected isochrones dated with a firn core reveal that the surface mass balance is higher on the south-eastern (upwind) slope than on the north-western (downwind) slope by $\sim 37 \%$, and this pattern has persisted for at least the past decade. Moreover, arches in radar stratigraphy suggest that the summit of the ice rise has been stable for $\sim 600$ years. Ensemble estimates of the mass balance using the input-output method show that this ice rise has thickened by $0.12-0.37 \mathrm{~m}$ ice equivalent per year over the past decade.
\end{abstract}

\section{Introduction}

Around $74 \%$ of the Antarctic coastline consists of floating ice shelves fed by outlet glaciers and ice streams (Bindschadler et al., 2011). These ice shelves, together with numerous pinning points (ice rises and rumples), regulate the outflow of the grounded ice (Dupont and Alley, 2005; Matsuoka et al., 2015; Fürst et al., 2016). Embedded into an ice shelf, an ice rise creates a zone of compression upstream of the ice rise that buttresses the ice shelf (Borstad et al., 2013). However, downstream of the ice rise the tensile forces leave a weak region subject to crevasses and thinner ice shelves (Favier and Pattyn, 2015). Also, ice rises strongly influence regional surface mass balance (SMB) (Lenaerts et al., 2014) and can significantly alter the timing of deglaciation of the ice sheet (Favier and Pattyn, 2015; Favier et al., 2016). Hence, although relatively small in areal footprint, ice rises can have far-reaching effects on Antarctic ice-sheet dynamics.

Ice rises are also a useful resource for investigating the evolution and past climate in the coastal region. Englacial (isochronous) stratigraphy detected using radar has been widely used to constrain the evolution of ice rises and adjacent ice bodies over the past millennia (Conway et al., 1999; Nereson and Waddington, 2002; Hindmarsh et al., 2011; Siegert et al., 2013; Drews et al., 2015; Kingslake et al., 2016), supplementing ice-core-derived climate records (e.g. Mulvaney et al., 2002, 2014).

The $2000 \mathrm{~km}$ long coastline of Dronning Maud Land (DML, $20^{\circ} \mathrm{W}-45^{\circ} \mathrm{E}$ ), East Antarctica, consists of numerous outlet glaciers and ice shelves punctuated by some 30 ice rises (Matsuoka et al., 2015). These ice rises most likely contribute significantly to the dynamics and mass balance of this region. In addition, their study provides clues to the evolution of this data-sparse region (Mackintosh et al., 2014). So far, only two ice rises have been investigated in DML: Derwael Ice Rise $\left(26^{\circ} \mathrm{E}\right)$ in Roi Baudouin Ice Shelf (Drews et al., 2015) and Halvfarryggen Ice Dome $\left(6^{\circ} \mathrm{W}\right)$ between Jelbartisen and Ekstromisen ice shelves (Drews et al., 2013). Both ice rises are grounded on flat beds $\sim 200 \mathrm{~m}$ below the current sea level, show large SMB contrasts across upwinddownwind slopes and have dynamic characteristic times of hundreds of years. Stratigraphic evidence shows that both of 

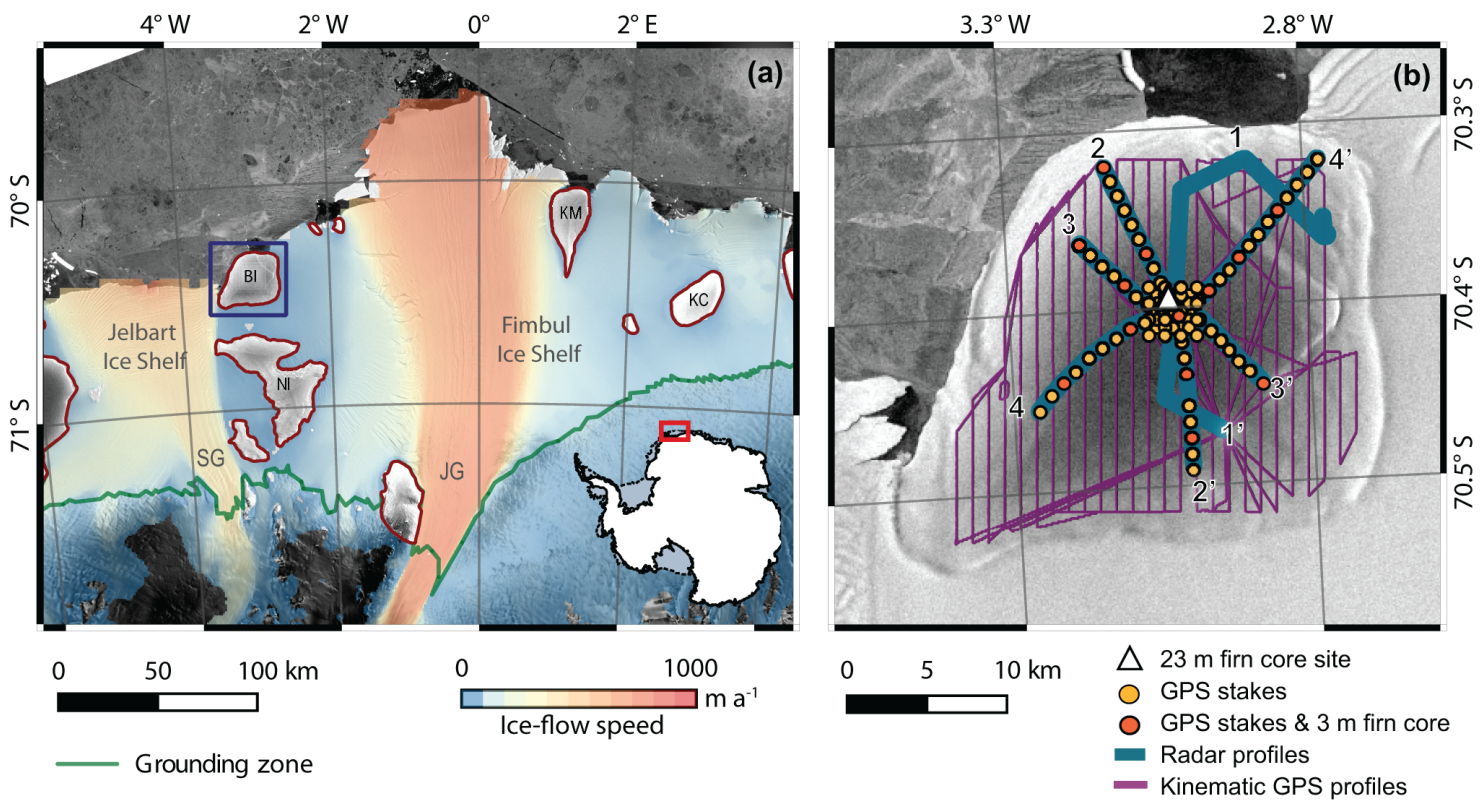

Figure 1. Blåskimen Island, western DML. (a) Blaskimen Island (BI in blue square) located between the Fimbul and Jelbart ice shelves. Inset shows the coverage of this map. Ice rises are outlined in red (Moholdt and Matsuoka, 2015), and the grounding zone of the ice sheet is illustrated in green (Bindschadler et al., 2011). The colour scale shows flow speed of the ice sheet and ice shelf (Rignot et al., 2011). The background of both panels is Radarsat-1 satellite imagery (Jezek et al., 2002). Acronyms stand for BI: Blåskimen Island, JG: Jutulstraumen Glacier, KM: Kupol Moskovskij, KC: Kupol Ciolkovskogo, NI: Novyy Island, and SG: Schytt Glacier. (b) Close-up view of Blåskimen Island. Pink curves show kinematic GPS profiles used to determine the surface topography and blue curves show radar profiles. Yellow circles show GPS stake positions for ice-flow measurements. Red circles show GPS stake positions where a $3 \mathrm{~m}$ long firn core was also drilled. The white triangle shows the location where the $23 \mathrm{~m}$ long firn core was drilled. Maps are projected to the Antarctic Polar Stereographic view (EPSG3031).

these ice rises have been in near-steady state over the last several millennia (3000-5000 years), despite being separated by $\sim 1200 \mathrm{~km}$ along the coast with variable glaciological settings. For example, along the DML coast between the two ice rises, SMB can vary by at least a factor of 2, depending on surface topography, storm tracks, and wind direction (King, 2004; Lenaerts et al., 2014). This region also consists of several ice shelves and outlet glaciers with flow speeds varying by a factor of 4 (Rignot et al., 2011). These existing observations underscore the requirement for further detailed investigations of ice rises in DML.

To elucidate the current status and past evolution of this coastal region, we made field measurements of Blåskimen Island, an isle-type ice rise located west of the Fimbul Ice Shelf at the calving front (Fig. 1a). Here we present surface and bed topography, surface-flow-velocity measurements, and the SMB of Blåskimen Island. Our analysis of these data implies that the ice rise has thickened by $0.12-0.37 \mathrm{~m} \mathrm{a}^{-1}$ (ice equivalent or $0.24-0.75 \mathrm{~m} \mathrm{a}^{-1}$ in surface elevation) over the past decade.

\section{Blåskimen Island}

Blåskimen Island (Fig. 1; total area $651 \mathrm{~km}^{2}$ Moholdt and Matsuoka, 2015) is the most seaward of a series of isle-type ice rises (surrounded by floating ice or ocean) that partitions the Jelbart Ice Shelf from the Fimbul Ice Shelf. Jelbart Ice Shelf is fed by the Schytt Glacier, which is slower by a factor of 2 and narrower than the Jutulstraumen Glacier, which feeds into Fimbul Ice Shelf (Rignot et al., 2011). Jutulstraumen Glacier, one of the largest outlet glaciers in DML (Høydal, 1996) is buttressed towards its western calving front by four small ice rises and rumples near Blåskimen Island. Overall, ice flow to the south of Blåskimen Island is slow, with open ocean to the north; ice flow to its east is also slowed by the ice rises and rumples on the western shear margin of the otherwise fast-flowing Fimbul Ice Shelf. As a result, the fastest flow near Blåskimen Island occurs to its west, where it abuts the eastern shear margin of Jelbart Ice Shelf. This overall setting implies that currently Blåskimen Island alone has limited impact on the continental grounding line and ice flux from the ice sheet. However, as Favier and Pattyn (2015) demonstrated how an ice rise aids the formation of rifts and ice-shelf break-ups on its seaward side, Blåskimen Island likely plays a more significant role than upstream ice rises in maintaining the current calving-front position. 


\section{Field measurements and data processing}

To estimate the mass balance of the ice rise, we made field measurements on Blåskimen Island during the austral summers of 2012-2013 and 2013-2014. The measurements included kinematic and static GPS surveys (Sect. 3.1), shallowand deep-sounding radar profiling (Sect. 3.2) as well as firn coring and borehole temperature measurements (Sect. 3.3). The location of these measurements is shown in Fig. $1 \mathrm{~b}$.

\subsection{Kinematic and static GPS surveys}

To develop digital elevation models (DEMs) of the ice-rise surface, we conducted kinematic GPS surveys using Trimble dual-frequency receivers. Two units were installed near the ice-rise summit, one acting as a base station and one for redundancy. Five rover stations were mounted on snowmobiles that moved at $\sim 15 \mathrm{~km} \mathrm{~h}^{-1}$. Our survey resulted in surfaceelevation measurements with an average interval of $\sim 4 \mathrm{~m}$ along the survey transects, the latter which are spaced $0.8-$ $1 \mathrm{~km}$ from each other. To locate the ice rise's summit, we ran additional surveys near the summit and in the eastern part of the ice rise where satellite imagery shows surface lineations (light grey feature over dark grey in Fig. 1b).

To measure the surface-flow velocities, we installed $3 \mathrm{~m}$ long hollow aluminium stakes at 97 locations on Blåskimen Island. The stakes were installed $\sim 1 \mathrm{~m}$ into the snowpack. We did not use any anchor to resist vertical motion of the stake. Out of these, 56 stakes were installed along the six steepest descent paths as determined with the surface DEM. To discern small ice-flow speeds within $2.5 \mathrm{~km}$ of the summit, we installed the other 41 stakes there. The stakes were occupied for $\sim 20 \mathrm{~min}$ to determine their lateral positions (e.g. Conway and Rasmussen, 2009; Matsuoka et al., $2012 b$ ), and 90 were reoccupied in January 2014, the remaining seven being lost to snow burial or found to be tilting by $>20^{\circ}$. Due to possible motion of the stakes relative to the firn and firn densification, we did not use GPS-measured vertical positions to determine ice-thickness changes. Nevertheless, we measured their heights to the snow surface to estimate the SMB over the year.

Instantaneous kinematic and average static-rover station locations were determined relative to the base stations for each field season using TRACK software, part of the GAMIT-GLOBK GPS package (Herring et al., 2010). Base-station positions for each field season were determined using the Canadian geodetic precise point positioning system (CSRS-PPP; https://webapp.geod.nrcan.gc. ca/geod/tools-outils/ppp.php). These base stations moved negligibly over the 5 days of GPS campaigns each year (i.e. less than the $\sim 1 \mathrm{~cm}$ lateral error of each GPS location). To convert heights above the WGS84 ellipsoid to heights above local sea level, we subtracted $13 \mathrm{~m}$ of geoid height uniformly provided by the GOCE gravity product (https://earth.esa.int/web/guest/data-access/ browse-data-products/-/article/goce-gravity-fields-5777).

\subsection{Ice-penetrating radar profiling}

To reveal the ice thickness and englacial isochronous stratigraphy, we collected common-offset radar transects along four of the steepest-descent paths concurrent with the GPS stake locations. These radar transects were collected with a $2 \mathrm{MHz}$ ground-based radar system with resistively loaded dipole antennas (Matsuoka et al., 2012a). We also operated a GSSI/SIR3000 radar with a $400 \mathrm{MHz}$ antenna to detect stratigraphy within the top $\sim 50 \mathrm{~m}$ of the ice rise (Hawley et al., 2014). Both radar surveys were collected with snowmobiles moving at $8-10 \mathrm{~km} \mathrm{~h}^{-1}$ and towing the antennas. The antenna positions were determined using kinematic GPS attached to the snowmobiles. The measurements resulted in an average radar-trace spacing of $\sim 5 \mathrm{~m}$ for the deepsounding radar and $\sim 0.25 \mathrm{~m}$ for the shallow-sounding radar.

Post-processing included using a dewow filter, an Ormsby band-pass filter, and depth-variable gain functions. To calculate ice thickness, we assumed a radio-wave propagation speed of $169 \mathrm{~m} \mathrm{ss}^{-1}$ and added a firn correction term of 4$6 \mathrm{~m}$ to account for faster propagation in the firn. The correction was estimated using the modelled depth profiles of the density along the radar profile based on firn-core density observations and shallow-radar data, as further discussed in Sect. 4.1.

\subsection{Firn cores and borehole-temperature measurements}

To record the stratigraphy (visual, chemical, isotopic, and dielectric), we drilled a $23 \mathrm{~m}$ long firn core near the icerise summit. The core was dated back to 1996 by counting annual cycles of oxygen isotopes and by identifying volcanic horizons using non-sea-salt sulfate data (Vega et al., 2016). The resulting SMB in the past 17 years ranges between $0.44 \mathrm{~m} \mathrm{a}^{-1}$ in 2004 and $1.32 \mathrm{~m} \mathrm{a}^{-1}$ in 2011. (Throughout this paper, we give mass balance and SMB as metres of ice equivalent.) The values give a mean SMB in this period of $0.76 \mathrm{~m} \mathrm{a}^{-1}$.

We installed a thermistor string in the borehole and measured temperature profiles from the surface to $20 \mathrm{~m}$ depth. Within $25 \mathrm{~h}$ after drilling finished, temperatures stabilized at each depth within $\pm 0.1{ }^{\circ} \mathrm{C}$ of variation. At depths between 8 and $12 \mathrm{~m}$ the temperature was $\sim-16.2^{\circ} \mathrm{C}$.

Separately, we drilled nine $3 \mathrm{~m}$ long firn cores (see Fig. $1 \mathrm{~b}$ for locations), then measured their core volumes and weights to determine the spatial variations of surface density. Hereafter, we refer to mean density in the top $3 \mathrm{~m}$ as surface density. Measured surface density through firn cores varies by $\sim \pm 2.5 \%$ over the ice rise, with a mean value of $453 \mathrm{~kg} \mathrm{~m}^{-3}$ (uncertainty: $3 \%$ or $14 \mathrm{~kg} \mathrm{~m}^{-3}$ ). However, no distinct pattern in surface density variation was observed in terms of eleva- 
tion or slope direction. We then used the bilinearly interpolated surface density to estimate SMB.

\section{Analytical methods}

\subsection{Surface mass balance}

We estimated SMB using two methods. The first method uses the heights of GPS stakes above the snow surface. The second method uses isochronous radar reflectors profiled with the shallow-sounding radar. Both methods require surfacedensity distribution measurements. The stake method is simpler and provides insight into SMB pattern over the ice rise for the period of 2013-2014. The radar method has higher uncertainties, but provides a longer-term view of past SMB patterns.

For the stake method, we estimated SMB at each stake by multiplying the measured stake-height differences by the measured surface density. Considering measurement errors and uncertainty accounting for snow densification (Eisen et al., 2008), this estimate has an overall uncertainty of $\pm 6 \%$. We considered the sinking of the stake under its own weight to be minimal, as the observed surface densities are high.

For the radar method, we derive SMB from dated radar reflectors assuming that radar reflectors are isochronous (Richardson et al., 1997). In our analysis, we also assumed that the effects of vertical strain (thinning after the deposition of snow) on reflector depths are negligible, so that thickness of an ice layer bounded by the radar reflectors is solely controlled by the differences in SMB (Waddington et al., 2007). With these assumptions, the shallow-layer approximation holds when the depth $h$ (ice equivalent) of a radar reflector is much smaller than the local ice thickness $H(h \ll H)$. For our case, $h / H$ is less than 0.04 and thus the shallow-layer approximation is in most cases valid.

However, the shallow-layer approximation may not be valid in areas where vertical strain rates are large, such as in the region near an ice-flow divide; hereafter just "divide" (Kingslake et al., 2014; Gillet-Chaulet, 2011). In this region, accumulated effects of variable vertical strain can result in upward arches in isochrones (Fig. 2c), so-called Raymond arches (Raymond, 1983), which have been found at many other ice rises (e.g. Vaughan et al., 1999; Conway et al., 1999; Nereson and Raymond, 2001). Similar upward arches can also be caused by anomalously low SMB near the summit, possibly due to wind erosion (Drews et al., 2013, 2015).

Vaughan et al. (1999) demonstrated that the amplitudes of upward arches induced by anomalous SMB increases linearly with ice-equivalent depth, whereas the Raymond effect makes the amplitude increase quadratically. We used this criterion to diagnose the origin of shallow upward arches near the current summit (Fig. 2b) as follows. First, we derived the ice-equivalent depth of the reflectors, assuming that firn density does not vary laterally. For this purpose, we used the depth profile of density $\rho(z)$ at the core site. We estimated local propagation speed $v(z)$ at depth $z$ using the relationship between density and refraction index $n(z)$ from Kovacs et al. (1995). Specifically,

$$
v(z)=\frac{c}{n(z)}=\frac{c}{1+0.851 \rho(z)},
$$

where $c$ is the speed of light in a vacuum $\left(300 \mathrm{~m} \mathrm{ss}^{-1}\right)$. Then, we estimated two-way propagation time $t(z)$ to each depth $z$ :

$t(z)=\int_{0}^{z} \frac{2}{v(z)} \mathrm{d} z$.

Secondly, using these ice-equivalent depths $z$, we measured arch amplitudes from the arch top to the baseline defined with reflector depths $1 \mathrm{~km}$ from both sides of the arch.

Under the shallow-layer approximation, we accounted for density variations using two methods. The first method accounts only for vertical variations in density and ignores any lateral variations. For this purpose, we used the measured densities of the $23 \mathrm{~m}$ long core. The second method involves simultaneously inverting for spatial variations in density, temperature, and SMB (Brown and Matsuoka, 2017). It uses an optimization inversion routine to solve for the best fit between a steady-state firn density model (Herron and Langway, 2010) and the measured two-way travel times to multiple isochrones identified in shallow-radar profiles. Our optimization routine is constrained by surface densities measured at 13 locations along the shallow-radar profile as well as the measured depth-density profile along the $23 \mathrm{~m}$ long firn core.

The former method is not strictly valid, because the surface density varies by $\sim \pm 2.5 \%$ and possible variations in SMB add more complexities in density at depths away from the core site. The latter method is also not strictly valid as it solves for the best fit at all locations to a steady-state firn densification model. Firn-core analysis shows no significant temporal trend, but large year-to-year variations by a factor of 3 over the past 17 years (Vega et al., 2016). Nevertheless, the model fits the measured density well (within $95 \%$ confidence bounds of the fit). Although these two methods use distinct assumptions, we find that they give similar patterns (e.g. Fig. 2a) and thus provide more confidence in SMB estimates.

\subsection{Mass balance of the ice rise}

We applied the input-output (I-O) method (e.g. Rignot and Kanagaratnam, 2006; Conway and Rasmussen, 2009; Zwally and Giovinetto, 2011) to individual columns over the ice rise (Sect. 4.2.1). The I-O method calculates the mass balance as a difference between incoming $Q_{\text {in }}$ and outgoing $Q_{\text {out }}$ fluxes from all the sides of a column, with SMB $\left(M_{\mathrm{SMB}}\right)$ over the added column area. As a one-dimensional thermomechanical model (Neumann et al., 2008) shows no basal melt 



Figure 2. Cross sections of the ice rise along the flow line 2-2' (Fig. 1b). (a) Surface slope (500 m running mean, absolute number, left axis) and SMB (right axis). The SMB derived from stake heights is indicated by + markers. Red curves show the two SMB estimates derived from radar data, with the solid curve assuming only vertical variability in density and the dashed curve accounting for both vertical and lateral variability in density. (b) $400 \mathrm{MHz}$ radargram. Three englacial reflectors are highlighted in black, which are dated with the $23 \mathrm{~m}$ long firn core (vertical bar) and used to determine SMB. (c) $2 \mathrm{MHz}$ radargram. Data are shifted using the GPS-measured surface elevations to show the topography.

for the geothermal-flux estimate in this region $\left(57 \mathrm{~mW} \mathrm{~m}^{-2}\right.$; Fox Maule et al., 2005), we ignored basal melting. Moreover, radargrams show no anomalous features in the radar reflection from the bed that could indicate basal melting (Fig. 2c).

The ice-flow fluxes through an ice column are calculated as

$Q=\rho \gamma u_{\perp} h$.

Here, $\rho$ is the density of a column, and $\gamma$ is a dimensionless factor that scales the measured surface-flow speed $u_{\perp}$ normal to the gate to depth-averaged speed $u_{\mathrm{av} \perp} ; u_{\mathrm{av} \perp}=\gamma u_{\perp}$, with $\gamma \leq 1$. The relation requires that ice-flow direction does not change with depth, which seems valid over relatively flat bed terrain underneath the ice rise (Sect. 5.1).

\subsubsection{Constraining $\gamma$}

The parameter $\gamma$ is a function of local surface slope, ice thickness, ice temperature, and ice rheology (Cuffey and Paterson, 2010). Assuming isothermal ice flow over a non-sliding bed and using the shallow-ice approximation, $\gamma=\frac{(n+1)}{(n+2)}$, where $n$ is the creep exponent of Glen's flow law 
(Cuffey and Paterson, 2010, p. 310). Previous studies on divide flow suggest that $n$ lies between 3 and 5 (Martín et al., 2009a, b; Drews et al., 2015; Gillet-Chaulet, 2011), giving a $\gamma$ between $0.80(n=3)$ and $0.86(n=5)$. However, due to ice-temperature variations and ice-divide effects, the latter of which invalidate the shallow-ice approximation, the range of $\gamma$ should be wider. For example, Reeh (1988) showed that near the divide, $\gamma$ can be close to 0.5 when $n=3$ and ice is isothermal. However, as ice becomes warmer at greater depths, the deeper ice is presumably softer than the shallower ice, implying that $\gamma$ is larger. Hence, it is reasonable to assume that $0.5 \leq \gamma \leq 1$. Raymond (1983) used an isothermal model, and Hvidberg (1996) used a thermomechanical model to constrain the range of $\gamma$ near the divide. Both showed that $\gamma$ varies the most near the divide, being smallest right at the divide.

Outside of the divide region by several ice thicknesses $H$ or more, $\gamma$ becomes less variable. For isothermal two-dimensional (divide) flow within $8 H$ of the divide, $0.61 \leq \gamma \leq 0.75$ (Raymond, 1983) and within $10 H$ of the divide, $0.56 \leq \gamma \leq 0.77$ (Hvidberg, 1996). Also within $10 \mathrm{H}$ of the divide, the case of thermomechanical flow gives $0.69 \leq \gamma \leq 0.86$ (Hvidberg, 1996) and the case of isothermal axisymmetric radial flow gives $0.54 \leq \gamma \leq 0.76$ (Hvidberg, 1996). Although radial flow leads to a larger divide region, $\sim 70 \%$ of the changes in $\gamma$ still happen within $4 H$ of the divide. Therefore, for the set-ups discussed below (with an average extent of $\sim 9 \mathrm{~km}$ or 18 ice thicknesses from the divide), $\gamma$ remains effectively uniform.

In each estimate below, we assume a spatially uniform $\gamma$ and examine ensemble results within the plausible range of $0.7-0.9$. As ice rheology has a memory through ice temperature and crystal fabric, a more accurate determination of $\gamma$ requires knowledge of ice-rise evolution in past millennia. Such knowledge requires detailed ice-flow modelling, which is beyond the scope of this study.

\subsubsection{Estimate set-ups}

Here we estimate mass balance for three set-ups: (i) several flow bands along GPS stakes and radar profiles, (ii) polygons bounded by GPS stakes, and (iii) uniformly distributed square columns (grid) on the ice rise. For (ii), values are averaged over individual polygons. The flow band set-up relies more on direct field measurements, but has very limited spatial coverage. The polygon and grid set-ups have good spatial coverages, but they rely upon data interpolations. Because it is difficult to accurately determine the net uncertainties associated with such data interpolations, we used two set-ups (polygon and grid) with distinct data interpolations and consider the resulting difference between them as an estimate of these net uncertainties.

\section{Flow band set-up}

In this method, we calculated mass balance along ice-flow bands of varying widths along three slopes of the ice rise. We define a flow band width to account for flow divergence and convergence along the flow band, assuming that ice flows along the steepest-descent path on the surface. Flow band width at the downslope end is taken as $1 \mathrm{~km}$, and for each flow band, the steepest-ascent paths are determined from two points $0.5 \mathrm{~km}$ away from the most downstream GPS stake. We used ascent path instead of descent, because the surface topography near the summit is much less distinct and consequently the divergence estimate is more sensitive to small topographic changes. We rejected three flow profiles out of six, because the GPS markers were not within the defined flow band. Along the remaining three flow bands, their widths vary by a factor of 1.4-3.6. This variation depends on the initial band width ( $1 \mathrm{~km}$ used here), but over the range of the initial band width between 0.9 and $2.5 \mathrm{~km}$, the band width estimates vary only $\sim 3 \%$. We further divided the flow bands into three columns based on the available data and calculated mass balance as per the $\mathrm{I}-\mathrm{O}$ method.

\section{Polygon set-up}

As ice rises are expected to show slope-dependent SMB features (King, 2004; Lenaerts et al., 2014), it is probable that mass balance could also have similar features. To account for a possible slope dependence, this set-up involved dividing the ice rise into 19 polygons with respect to the surface slope direction and data availability. All sides of these polygons act as a flux gate. Ice thickness and surface-flow velocities are available at each corner of these polygons. We observed some cases in which ice was thicker at one corner, but the flow was faster at the other corner. To address such variations along a flux gate, we divided each gate into 10 subgates and estimated the flux at each subgate, rather than calculating mass flux using single values averaged over an entire gate.

\section{Grid set-up}

This set-up involves dividing the ice rise into a grid with $200 \mathrm{~m}$ long square columns and estimating mass balance for each column. The mass-balance values are then averaged over each polygon of the above polygon set-up. By comparing these two set-ups, we can test how data interpolations affect the mass-balance estimate. We calculate mass balance $M_{\mathrm{MB}}$ by calculating the continuity equation to each grid element as

$M_{\mathrm{MB}}=\frac{\partial h}{\partial t}=M_{\mathrm{SMB}}+\left(\frac{\partial u}{\partial x}+\frac{\partial v}{\partial y}\right) H+\left(u \frac{\partial h}{\partial x}+v \frac{\partial h}{\partial y}\right)$,

where $u$ and $v$ are the components of ice-flow vectors in the rectangular (local coordinate) directions $x$ and $y$, and $h$ is the variable for ice thickness. We bilinearly interpolated the measured $u, v, M_{\mathrm{SMB}}$, and $H$ into grids. 


\section{Results}

\subsection{Topography and surface-flow velocity}

Figure 3a shows surface elevations derived from kinematic GPS surveys using bilinear interpolation. The summit is $410 \mathrm{~m}$ a.s.l. and is $\sim 350 \mathrm{~m}$ higher than the surface of the ice shelf on the southern side (ice-shelf elevation is taken from Fretwell et al., 2013). From the summit, the elevation drops gradually towards the edges of our survey region in all directions, giving a dome-like shape to the ice rise. A pronounced ridge extends from the summit to the south-west. The eastern flank shows locally steep slopes and a basin in the north-east with an overall lower, less tilted surface. The eastern steep slopes and the south-western ridge are consistent with lineations observed in satellite imagery (light grey feature over dark grey in Fig. 1b). Along a profile through the summit (2-2' in Fig. 1b), the absolute surface slope smoothed over $500 \mathrm{~m}$ long segments ranges between 0.02 and 0.04 , except for the region within $\sim 0.5 \mathrm{~km}$ of the summit where the surface is virtually flat (Fig. 2a).

From the radar profiles (e.g. Fig. 2c), we located the bed to determine the ice thickness. The resulting thickness ranges between $374 \mathrm{~m}$ (first quartile) and $444 \mathrm{~m}$ (third quartile), with a mean value of $400 \mathrm{~m}$. The ice gradually becomes thinner in all directions away from the summit. Considering uncertainty associated with digitization of the bed reflector, data sampling, and firn correction, the uncertainty in the ice thickness is $\pm 5 \mathrm{~m}$.

The bed elevation here equals the surface elevation minus the ice thickness. At locations where radar data are available, the bed elevation is on average $110 \mathrm{~m}$ below the current sea level (i.e. $-110 \mathrm{~m}$ a.s.l.), ranging between -68 and $-125 \mathrm{~m}$ a.s.l. (first and third quartiles, respectively). The highest point ( $-22 \mathrm{~m}$ a.s.l.) on the bed occurs about $6 \mathrm{~km}$ north-east of the summit (along the $4-4^{\prime}$ profile; see Fig. 1b). We developed a bed DEM using bilinear interpolation (Fig. 3b). The bed of the central part of the ice rise is very flat; in this region, bed elevations vary only by $\sim 50 \mathrm{~m}$ within an area of $\sim 100 \mathrm{~km}^{2}$. Also, individual radar profiles show that this region is smooth (Fig. 2c). This low, flat, and smooth region extends from the summit vicinity towards north and north-west and constitutes the majority of the ice-rise bed. However, towards the southern end of the survey domain, the bed elevation decreases by $\sim 200 \mathrm{~m}$ over a horizontal range of $\sim 5 \mathrm{~km}$, resulting in a mean bed slope of $\sim 0.04$. Another steep bed region (0.03-0.04) occurs in the northeastern slope. These steeper regions in the bed are associated with steeper regions on the surface, although the surface is not as steep as the bed.

The surface-flow velocity measurements are shown in Fig. 3c. The GPS stakes within $2 \mathrm{~km}$ of the summit moved only negligibly $\left(<0.1 \mathrm{~m} \mathrm{a}^{-1}\right)$. The displacement of stakes outside the summit region is larger and increases downstream; ice flows less than $3 \mathrm{~m} \mathrm{a}^{-1}$ within $4 \mathrm{~km}$ of the sum-
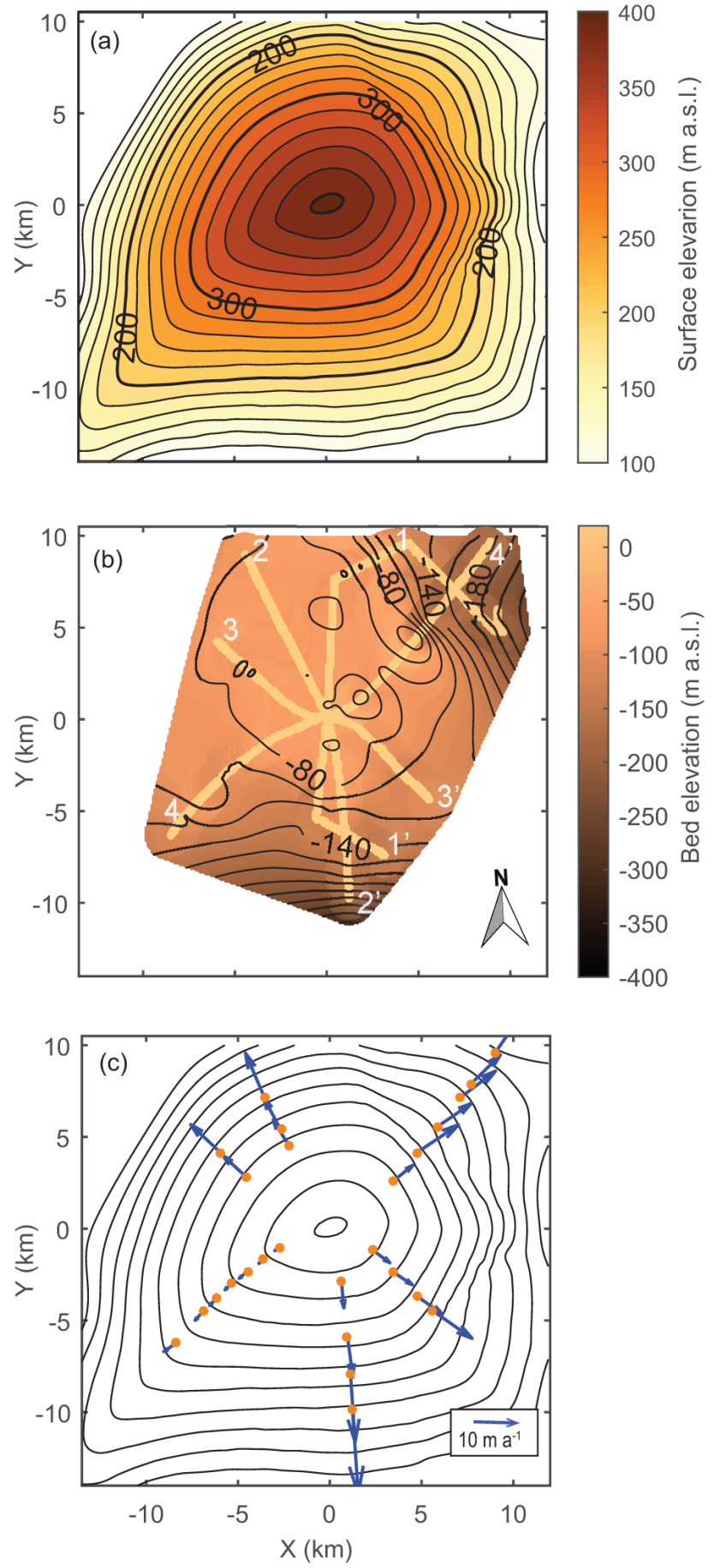

Figure 3. Ice-rise topography and flow velocities. The local coordinates are parallel to the polar stereographic coordinates EPSG3031 and centred at the ice-rise summit. The elevations are relative to the geoid surface. (a) Surface elevation. Contour intervals are $20 \mathrm{~m}$ (b) Bed elevation, also with $20 \mathrm{~m}$ contour intervals. Radar profiles used to derive the bed topography are highlighted in yellow to show the data availability. (c) Ice-flow velocities. Surface ice-flow velocities (blue arrows originated from orange circles) overlaid on surface topography (30 m contour intervals). Kinematic GPS survey locations are shown in Fig. 1b. GPS stakes near the summit did not give significant results and thus are not shown here. 


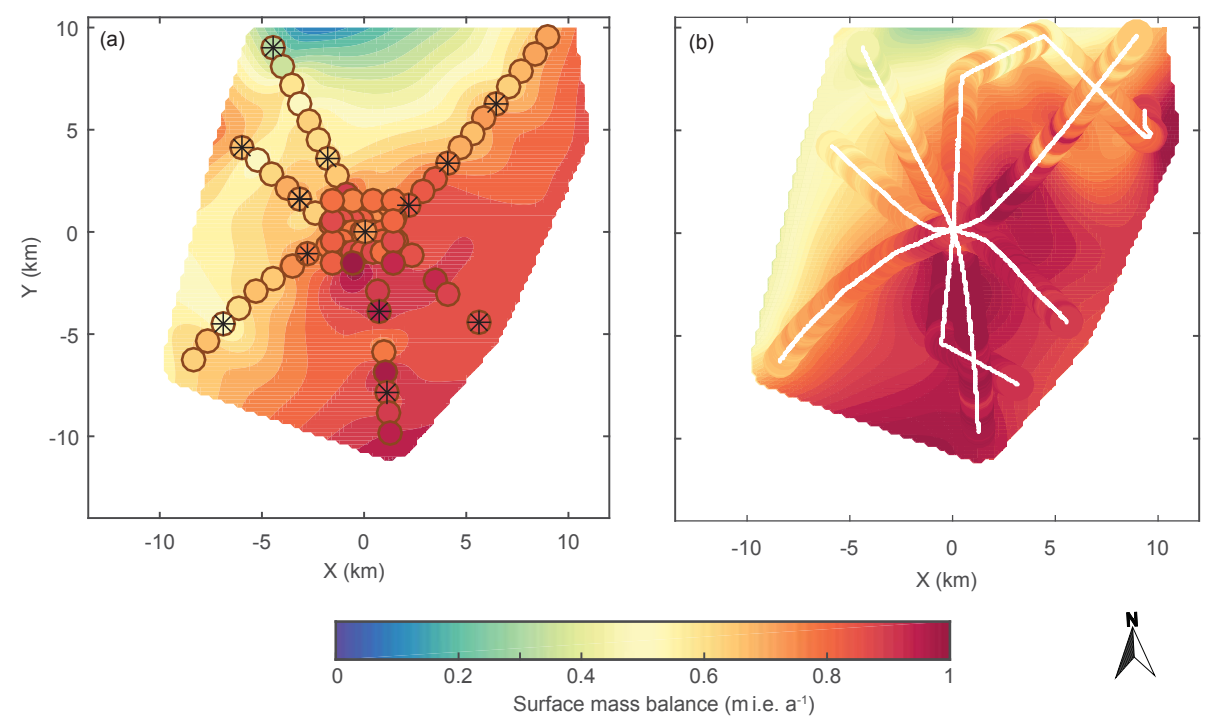

Figure 4. Surface mass balance (SMB). (a) SMB during 2013-2014 interpolated from stake measurements. Circles show the locations of the installed stakes. Wheel spokes inside of the circles show the locations of 13 surface-density measurements. (b) SMB over the past decade estimated from radar. It accounts only for the vertical variability of density. White curves show the location of radar profiles. The $23 \mathrm{~m}$ long firn core was drilled near the crossover of all profiles at the summit.

mit and $10-15 \mathrm{~m} \mathrm{a}^{-1}$ downslope. Ice flows slowest along the ridge towards the south-west, whereas the fastest flow is along the southern section of flow line $2-2^{\prime}$. The estimated positions have a mean precision of 4.9 and $5.1 \mathrm{~cm}$ for the east-west and north-south components, leading to a processing uncertainty on the velocity of $\pm 7 \mathrm{~cm} \mathrm{a}^{-1}$. This does not include uncertainty associated with any tilt of the stakes. Nevertheless, as the velocities outside the summit area range between 4 and $15 \mathrm{~m} \mathrm{a}^{-1}$, and the observed tilts were small, we considered this uncertainty to be negligible.

\subsection{Surface mass balance}

The mean SMB from 90 stake-height measurements across Blåskimen Island is $0.78 \mathrm{~m} \mathrm{a}^{-1}$ for the period between January 2013 and January 2014 (Fig. 4a). SMB varies by a factor of 3.3 over the study area $\left(0.28-1.03 \mathrm{~m} \mathrm{a}^{-1}\right)$, with $80 \%$ of the values ranging between 0.69 and $1.03 \mathrm{~m} \mathrm{a}^{-1}$. The SMB shows a distinct spatial pattern: larger in the south-eastern slope and smaller in the north-western slope. The surface is rougher due to sastrugi in the low-SMB region, but smoother and softer in the high-SMB region, indicating strong influence of the wind. The summit vicinity has a large number of stakes that show small variations of SMB, but without any distinct pattern.

The shallow-sounding radar visualizes continuous reflectors within the firn (Fig. 2b). No major disruptions are observed that can be associated with surface melt or strong wind scour. Therefore, we assume these continuous reflectors are isochrones (Richardson et al., 1997). With this assumption, we can associate firn-core ages to radar reflectors. We tracked three such reflectors to almost the full extent of the radar surveys; at the site of $23 \mathrm{~m}$ long core, they are at $8.4 \mathrm{~m}$ depth (or $2.15 \mathrm{~m}$ ice-equivalent depth; dated 2011 or 3 years before the survey by Vega et al., 2016), $11.9 \mathrm{~m}$ (4.2 m; 2009), and $12.8 \mathrm{~m}(6.9 \mathrm{~m} ; 2005)$.

To judge whether the reflector depths are controlled primarily by SMB or the Raymond effect (Sect. 4.1), we measured the amplitudes of arches near the current divide. Due to the shallowest reflector having insignificant amplitude, we used just the two deeper reflectors of the three that were used for SMB estimates. In addition, we measured arch amplitudes of six more reflectors at greater depths. These reflectors range between $\sim 4$ and $\sim 35 \mathrm{~m}$ ice-equivalent depth (Fig. 2b). We analysed the arch amplitudes in this depth range to resolve their depth variations. All four radar profiles across the summit (Fig. 1b) show that the arch amplitude increases linearly with depth (Fig. 5). Therefore, we conclude that the shallow-layer approximation can be used all along the radar profiles, and thus the three radar reflectors within the top $\sim 7 \mathrm{~m}$ ice-equivalent represent spatial patterns of SMB.

The $23 \mathrm{~m}$ long core shows that the density varies $\sim 36 \%$ (450-655 $\mathrm{kg} \mathrm{m}^{-3}$ ) along its length and the 13 shallow cores show that the surface density varies $\sim \pm 2.5 \%$ horizontally. Among the three reflectors we analysed, the deepest reflector (12.8 $\mathrm{m}$ actual depth at the core site) has the largest depth range between $\sim 8$ and $\sim 15 \mathrm{~m}$. Thus, to make the SMB estimates more accurate, one should account for variable density.

Figure 2a shows the SMB averaged over the past 9 years (2005-2014) estimated using the two radar methods along the profile $2-2^{\prime}$. This profile, as well as the other 


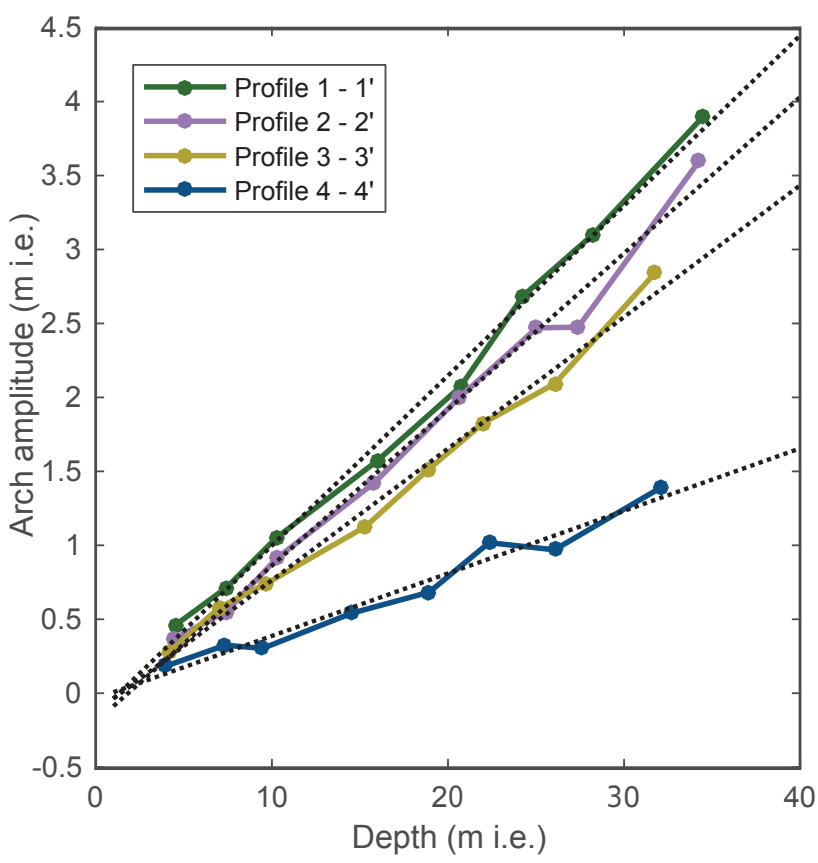

Figure 5. Depth variations of upward-arch amplitudes observed near the summit (Fig. 2b) along four radar profiles (Fig. 1b). Filled circles show the arch amplitudes and dotted lines show the linear fits.

profiles (not shown in Fig. 2a), show that the first estimate (accounting for the vertical density variations only) usually exceeds the second estimate (accounting for both lateral and vertical density variations) by about $5-10 \%$. The largest difference $\left(0.16 \mathrm{~m} \mathrm{a}^{-1}\right)$ was found in the region $1-6 \mathrm{~km}$ northeast of the summit along profile 4-4'. Except for this region, these two methods give nearly identical SMB spatial patterns along the radar profiles. Figure $4 \mathrm{~b}$ shows the SMB estimated using the first radar method. It gives the spatially mean value of $0.81 \mathrm{~m} \mathrm{a}^{-1}$, with the first and third quartiles of 0.71 and $0.93 \mathrm{~m} \mathrm{a}^{-1}$ respectively. The second radar method has a mean value of $0.75 \mathrm{~m} \mathrm{a}^{-1}$, with first and third quartiles of 0.65 and $0.85 \mathrm{~m} \mathrm{a}^{-1}$ respectively.

Consider the uncertainties in SMB derived from dated radar isochrones. In broad categories, these arise from errors in (1) determining the depth of the reflector, (2) dating the firn core, and (3) estimating the cumulative mass above the reflector and its spatial variability. For the first source, we estimate the uncertainty to be within $\pm 10 \mathrm{~cm}$. For the combined errors in depth-age scale and error in linking it to radar reflector, we estimate this to be \pm 1 year. Finally, the density model used to fit the observations has an uncertainty of $\pm 3 \%$, whereas we see $\pm 3 \%$ variability in the surface density. Using standard error propagation, this results in an uncertainty of $\pm 11 \%$, a value that exceeds the uncertainty of $\pm 6 \%$ for the stake method.

\subsection{Mass balance}

We estimated mass balance over the 9-year period between 2005 and 2014 (Fig. 6), using the SMB estimate over this period. For other inputs to the estimate, we assumed that the present observations are representative of this period. For the mean value, the flow band set-up shows a mean mass balance of $+0.12 \pm 0.10$ and $+0.27 \pm 0.10 \mathrm{~m} \mathrm{a}^{-1}$ over the range of $\gamma$. The uncertainty $\left( \pm 0.10 \mathrm{~m} \mathrm{a}^{-1}\right)$ is estimated using the uncertainties in ice thickness $( \pm 5 \mathrm{~m})$, flow speed $\left( \pm 7 \mathrm{~cm} \mathrm{a}^{-1}\right)$, ice density after correcting for firn $( \pm 2 \%)$, and SMB $( \pm 11 \%)$ with propagation of errors.

The polygon and grid set-ups give very similar spatial patterns to each other. For these two set-ups, the mass-balance estimate is also affected by errors associated with data interpolation. Because it is difficult to determine these errors accurately, we used two set-ups (polygon and grid) with distinct data interpolations and consider the differences between them as an estimate of uncertainties associated with the data interpolation. We averaged mean mass-balance values of all ice columns for each set-up and for each $\gamma$. Figure 7 shows that, for a given $\gamma$, the polygon set-up gives the largest estimate, whereas the grid-set-up estimate is smaller by 0.02 $0.03 \mathrm{~m} \mathrm{a}^{-1}$. Because this difference is smaller than the uncertainty for the flow band-set-up estimate $\left( \pm 0.1 \mathrm{~m} \mathrm{a}^{-1}\right)$, interpolation errors probably do not dominate these results. Higher $\gamma$ values correspond to lower mass balance, and the sensitivity of mass balance to $\gamma$ is nearly uniform for individual columns.

For polygon and grid set-ups, all the columns show positive mass balance over the full $\gamma$ range, except for southeasternmost downstream polygon A3 (the slope-direction codes are shown in Fig. 6b). Along slopes C, E, and F, mass balance does not vary significantly along the slope, whereas mass balance of polygons along slopes A, B, and D is more variable. For the flow band set-up, six out of nine columns show positive mass balance, with columns CD3 and DE1 (see Fig. 6a for the slope-direction codes) being very close to balance. Column DE3 has negative mass balance in the north-west downstream, a region where the estimated flow divergence is anomalously large.

In summary, the measurements show that Blåskimen Island had positive mass balance between 2005 and 2014 . Thickening rates vary depending on the set-ups and the choice of $\gamma$. Over the range of $\gamma$ used here $(0.7 \leq \gamma \leq 0.9)$, the mean mass balance varies between $+0.12 \pm 0.10$ and $+0.27 \pm 0.10 \mathrm{~m} \mathrm{a}^{-1}$ for the flow band set-up, between +0.25 and $+0.37 \mathrm{~m} \mathrm{a}^{-1}$ for the polygon set-up, and between +0.21 and $+0.35 \mathrm{~m} \mathrm{a}^{-1}$ for the grid set-up. Outside the divide region, $\gamma$ tends to be higher (0.8-0.9; Sect. 4.2); consequently, the thickening rates lean towards the lower end of the estimate above. 

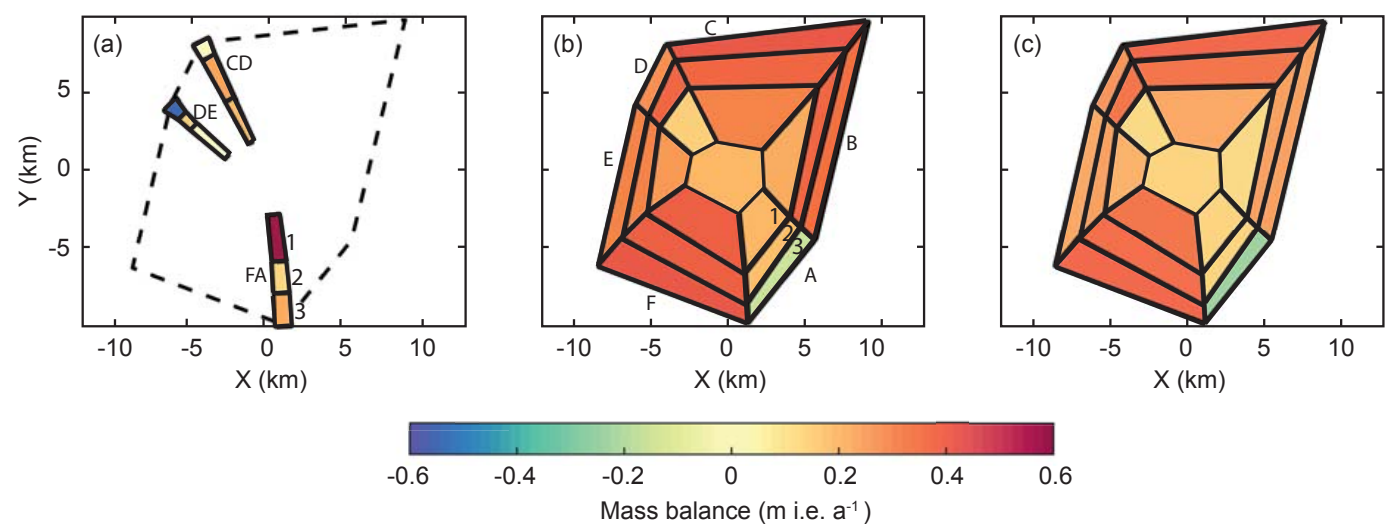

Figure 6. Recent mass balance when the fraction $\gamma$ of depth-averaged flow speed to the surface flow speed equals 0.8 . Results are derived from three set-ups. (a) Flow band set-up. The slopes (FA, CD, and DE) are divided into three columns (1-3, with 1 for most upstream in each slope). (b) Polygon set-up. The ice rise is divided into six slopes (A-F) with three polygons each (1-3, with 1 for most upstream in each slope) and a summit polygon. (c) Grid set-up. The dashed lines in (a) show the extent of the polygon and grid set-ups for comparison.

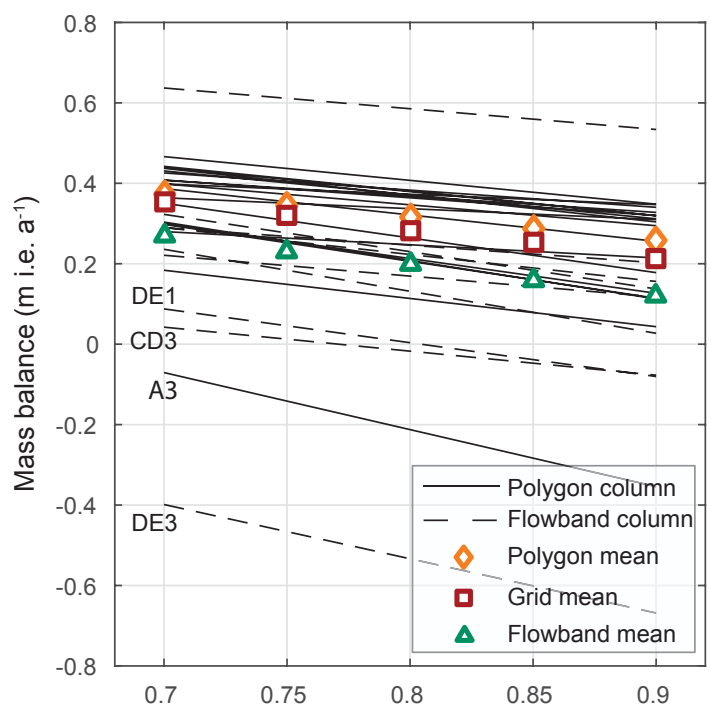

$\gamma$ (Fraction of depth-averaged flow speed to the surface flow speed)

Figure 7. Mass-balance estimates of individual polygonal columns (polygon set-up, solid lines) and flow band columns (flow band setup, dashed lines) in terms of $\gamma$, the fraction of the depth-averaged flow speed to the surface flow speed. Those derived with the grid set-up (not shown) are very similar to those with the polygon set-up. The ensemble-mean mass-balance estimates for each $\gamma$ are shown with symbols for all the set-ups. Columns discussed in the text are labelled.

\section{Discussion}

\subsection{Topographic characteristics}

According to a recent inventory of ice rises and rumples in Antarctica (Moholdt and Matsuoka, 2015; Matsuoka et al., 2015), Blåskimen Island $\left(651 \mathrm{~km}^{2}\right)$ has greater areal extent than $91 \%$ of isle-type ice rises (mean: $151 \mathrm{~km}^{2}$ ). Its summit is $410 \mathrm{~m}$ a.s.1., which is higher than $89 \%$ of the others (mean: $168 \mathrm{~m}$ a.s.1.). Maximum measured ice-flow speed $\left(15 \mathrm{~m} \mathrm{a}^{-1}\right)$ is larger than the mean value for the other isle-type ice rises $\left(13 \mathrm{~m} \mathrm{a}^{-1}\right)$. Also, the mean bed elevation at $-110 \mathrm{~m}$ a.s.l. is higher than $86 \%$ of the others $(-178 \mathrm{~m}$ a.s.1.). Overall, Blåskimen Island is one of the larger isle-type ice rises.

Our detailed surface DEM (Fig. 3a) reveals a number of surface topographic features that are smoothed over in continent-wide DEMs. For example, two widely used DEMs (Bamber et al., 2009; Fretwell et al., 2013) show different topography of the ice rise and elevations are off from our local DEM by $10-100 \mathrm{~m}$ at different places. Ice rises have much steeper slopes than the continental slope (Fig. 2a), which inherently requires high-spatial resolutions to represent the topography accurately. This missing detail could affect modelling SMB and surface density. Lenaerts et al. (2014) demonstrated that elevated topography associated with an ice rise causes orographic precipitation and the resulting precipitation shadow not only over the ice rise, but also on the adjacent ice shelves. Such variations could result in anomalous firn-density estimates over the ice shelves, which would result in ill-posed estimates of freeboard thickness and the resulting long-term changes of adjacent ice shelves.

Our local DEM confirmed that lineations in satellite imagery over Blåskimen Island appear where the surface slope has greater variability, with most lineations being associated with uneven bed topography. Such an association was originally proposed over Fletcher Promontory by Goodwin and Vaughan (1995). This agreement supports the use of satellite imagery as a remote means to explore first-order surface and bed topography. 


\subsection{Surface mass balance}

We found good agreement in the spatial patterns of stakemeasured SMB between 2013 and 2014, and radar-measured SMB between 2005 and 2014 (Fig. 4a and b). Relative thicknesses of three layers bounded by radar isochrones (and the surface) vary similarly along the profiles (Fig. 2b), from which we infer that spatial patterns of SMB have remained relatively constant over the 9-year period 2005-2014. SMB averaged over this period has a mean of $0.81 \mathrm{~m} \mathrm{a}^{-1}$ but varies along the radar profiles between $0.71 \mathrm{~m} \mathrm{a}^{-1}$ (first quartile) and $0.93 \mathrm{~m} \mathrm{a}^{-1}$ (third quartile).

Such large spatial variability in SMB has been observed on other Antarctic ice rises. For example, King (2004) showed that SMB on Lydden Ice Rise, Brunt Ice Shelf, is highly variable both at large (tens of kilometres) and small spatial scales (hundreds of metres). They demonstrated that large-scale variations are a result of orographic precipitation, whereas small-scale variations are a result of snow redistribution. On both scales, the contribution from sublimation was relatively small. They emphasize that SMB is sensitive to surface topography, with small variations in surface topography causing small changes in wind speed, which can cause large SMB variations due to the non-linear relationship between wind speed and snow transport. On Blåskimen Island, we compared the SMB values to local surface slope measured along the kinematic/radar profiles. Although we found no clear relationship between them, we did not sample along the prevailing wind direction, where the effect would be strongest.

The net impact of these mechanisms on SMB in the DML coast has been examined using the RACMO2 regional climate model (Lenaerts et al., 2014). Among all the ice rises included in their study, SMB varies by a factor of 2-6. On Blåskimen Island, we found that upwind slopes have 23 times the SMB than the downwind slopes, which is within the model prediction (2-4 times; Lenaerts et al., 2014). Similar SMB gradients are found over other ice rises in DML: 2-3 times over Halvfarryggen Ice Dome (Drews et al., 2013) and about 2 times over the Derwael Ice Rise (Drews et al., 2015). We observed numerous sastrugi and harder snow on the north-western downwind slopes, a clear indication of snow erosion-redistribution processes. Another feature occurs near the summit, where the surface is virtually flat; here, SMB is lowered by $\sim 10 \%$ over $\sim 0.5 \mathrm{~km}$. Similarly low SMB near the summit has been observed in the Halvfarryggen Ice Dome and the Derwael Ice Rise, where it was attributed to wind erosion (Drews et al., 2013, 2015).

\subsection{Present-day mass balance}

Among all factors that affect the mass balance, the ice-flow speed varies most widely about its mean value (57\%), as compared to that for SMB (17\%) and ice thickness (11\%). Consequently, the mass-balance distribution is more sensitive to the flow-speed distribution than the other factors. This also explains the low mass balance in the A slope (Fig. 6b). The downstream region of the A slope has a lower bed than the central flat basin. As the ice surface is steeper, ice flows faster in this region. Overall, despite the large upwinddownwind contrast in SMB (Fig. 4), differential mass flux compensates for the difference in SMB, so that no distinct mass-balance patterns occur (Fig. 6). Our mass-balance estimates show that Blåskimen Island is thickening almost everywhere, but the thickening rate is smaller near the summit than the flank. If this pattern persists for a long period, the ice rise would initially flatten. However, ice-flow velocities would probably adjust to the new topography, making the net impact of the ongoing differential thickening on ice topography difficult to predict.

\subsection{Long-term evolution}

Distinct upward arches in the ice stratigraphy up to $\sim 40 \mathrm{~m}$ depth are caused by low SMB near the summit. We observed upward arches below this depth (Fig. 2c), which are most likely Raymond arches. Regardless of its cause, the upward arch locations can be a proxy of the summit position in the past (Nereson et al., 1998).

The vertical alignment of the arches in the top $\sim 40 \mathrm{~m}$ below the summit (Fig. 2b) indicates that the summit position has been stable over the past several decades. In contrast, the deeper arches $(\sim 300 \mathrm{~m}$ a.s.l. and below) show more offset towards the south-east with increasing depth (radar profile $2-2^{\prime}$ shown in Fig. 2c). This trend also occurs in other radar profiles. This arch inclination may mean that the summit has migrated towards the north-west in the past. Present-day results show no clear signs of mass imbalance implying such a divide migration (Fig. 6). This may indicate recent changes in mass balance and/or it may indicate a limitation of our massbalance estimate due to a resolution (thousands of metres) that is coarser than the observed arch offset (100-400 m).

If the upward arches at greater depths are indeed Raymond arches, then the current summit position has likely been stable within several ice thicknesses over one characteristic time $T\left(=H / M_{\mathrm{SMB}}, \sim 610\right.$ years at Blåskimen Island $)$ or longer. If the summit position stays stable for a longer time, then the Raymond arches would further develop into double-peaked arches (Martín et al., 2009a), which are not clearly observed here. (We do find a small side arch, but this is caused by a bed bump nearby according to our initial ice-flow modelling.) According to Martín et al. (2009a), the double-peaked arches appear after several $T$, but reach a mature shape only after $\sim 10 T$ or so. Therefore, we speculate that the summit of Blåskimen Island has been stable within several kilometres at least in the past $\sim 600$ years but no longer than several millennia. 


\section{Conclusions}

We used geophysical methods to investigate Blåskimen Island, one of the larger isle-type ice rises at the calving front at the intersection of Fimbul and Jelbart ice shelves on the Dronning Maud Land coast. The ice rise was found to be dome shaped with a summit at $\sim 350 \mathrm{~m}$ above the adjacent ice shelf. It stands over a flat bed with a mean elevation of $110 \mathrm{~m}$ b.s.l. (below sea level). The ice flows from the summit towards the flank with speeds up to $15 \mathrm{~m} \mathrm{a}^{-1}$. We found good agreement in the spatial patterns of stake-measured surface mass balance between 2013 and 2014, and radar-measured surface mass balance between 2005 and 2014. Both showed higher surface mass balance on the upwind slope (south-east) than that on downwind slope (north-west) by $\sim 37 \%$. This variation was likely a result of orographic precipitation during storms. Using the input-output method for a range of parameters and column set-ups, we concluded that Blåskimen Island has been thickening over the past decade. Thickening rates could not be determined precisely, but ensemble results showed that the thickening rate averaged over the ice rise may be between 0.12 and $0.37 \mathrm{~m} \mathrm{a}^{-1}$. On longer timescales, we speculated that the summit of the ice rise has been stable within several kilometres at least in the past $\sim 600$ years, but no longer than several millennia.

Data availability. The data sets used or derived in this paper are available at https://data.npolar.no/project/ 19bacc06-f081-4615-ae05-12dae73345bf. It includes radar, GPS, and borehole thermistor data as well as ice thickness, surface flow velocity, and surface mass-balance data sets. The $23 \mathrm{~m}$ long firn-core data and their availability are described in Vega et al. (2016).

Author contributions. KM and JB designed the study. All three authors conducted fieldwork. VG led the overall data analysis and interpretations. JB prepared the GPS and GPR processing workflow, which VG adapted. JB also produced inversion SMB estimates. VG and $\mathrm{KM}$ prepared the manuscript and JB contributed to finalizing it.

Competing interests. Author Kenichi Matsuoka is a member of the editorial board of the journal.

Acknowledgements. This work was funded by grants from Norwegian Antarctic Research Expeditions (NARE) and the Center for Ice Climate and Ecosystems (ICE) of the Norwegian Polar Institute. Vikram Goel received a PhD studentship from National Centre for Antarctic and Ocean Research (NCAOR) through financial support from the Ministry of Earth Sciences (MoES), Government of India. We thank Harvey Goodwin, Kjetil Bakkland, Ørjan Karlsen, and Peter Leopold for their contributions to fieldwork. Troll Station of NARE and SANAE Station of the South African National Antarctic Programs provided field support. Tor Ivan Karlsen developed the low-frequency radar. Carmen P. Vega, Elisabeth Isaksson, and their team provided the depth-age data of the core. We thank Robert Bingham and two other anonymous reviewers and the editor Olaf Eisen for their constructive comments, which improved the manuscript significantly. Figure 1 was developed using a free GIS data package Quantarctica (quantarctica.npolar.no).

Edited by: Olaf Eisen

Reviewed by: Robert Bingham and two anonymous referees

\section{References}

Bamber, J. L., Gomez-Dans, J. L., and Griggs, J. A.: A new 1 km digital elevation model of the Antarctic derived from combined satellite radar and laser data - Part 1: Data and methods, The Cryosphere, 3, 101-111, https://doi.org/10.5194/tc-3-101-2009, 2009.

Bindschadler, R., Choi, H., Wichlacz, A., Bingham, R., Bohlander, J., Brunt, K., Corr, H., Drews, R., Fricker, H., Hall, M., Hindmarsh, R., Kohler, J., Padman, L., Rack, W., Rotschky, G., Urbini, S., Vornberger, P., and Young, N.: Getting around Antarctica: new high-resolution mappings of the grounded and freely-floating boundaries of the Antarctic ice sheet created for the International Polar Year, The Cryosphere, 5, 569-588, https://doi.org/10.5194/tc-5-569-2011, 2011.

Borstad, C. P., Rignot, E., Mouginot, J., and Schodlok, M. P.: Creep deformation and buttressing capacity of damaged ice shelves: theory and application to Larsen $\mathrm{C}$ ice shelf, The Cryosphere, 7, 1931-1947, https://doi.org/10.5194/tc-7-1931-2013, 2013.

Brown, J. and Matsuoka, K.: An optimization routine for estimating density distribution in firn, in preparation, 2017.

Conway, H. and Rasmussen, L. A.: Recent thinning and migration of the Western Divide, central West Antarctica, Geophys. Res. Lett., 36, L12502, https://doi.org/10.1029/2009GL038072, 2009.

Conway, H., Hall, B. L., Denton, G. H., Gades, A. M., and Waddington, E. D.: Past and future grounding-line retreat of the West Antarctic Ice Sheet, Science, 286, 280-283, https://doi.org/10.1126/science.286.5438.280, 1999.

Cuffey, K. M. and Paterson, W. S. B.: The Physics of Glaciers, Academic Press, Cambridge, Massachusetts, USA, 2010.

Drews, R., Martín, C., Steinhage, D., and Eisen, O.: Characterizing the glaciological conditions at Halvfarryggen ice dome, Dronning Maud Land, Antarctica, J. Glaciol., 59, 9-20, https://doi.org/10.3189/2013JoG12J134, 2013.

Drews, R., Matsuoka, K., Martín, C., Callens, D., Bergeot, N., and Pattyn, F.: Evolution of Derwael Ice Rise in Dronning Maud Land, Antarctica, over the last millennia, J. Geophys. Res.-Earth, 120, 564-579, https://doi.org/10.1002/2014JF003246, 2015.

Dupont, T. K. and Alley, R. B.: Assessment of the importance of ice-shelf buttressing to ice-sheet flow, Geophys. Res. Lett., 32, L04503, https://doi.org/10.1029/2004GL022024, 2005.

Eisen, O., Frezzotti, M., Genthon, C., Isaksson, E., Magand, O., van den Broeke, M. R., Dixon, D. A., Ekaykin, A., Holmlund, P., Kameda, T., Karlöf, L., Kaspari, S., Lipenkov, V. Y., Oerter, H., Takahashi, S. and Vaughan, D. G.: Ground-based measurements of spatial and temporal variability of snow accumulation in East Antarctica, Rev. Geophys., 46, RG2001, https://doi.org/10.1029/2006RG000218, 2008. 
Favier, L. and Pattyn, F.: Antarctic ice rise formation, evolution, and stability, Geophys. Res. Lett., 42, 4456-4463, https://doi.org/10.1002/2015GL064195, 2015.

Favier, L., Pattyn, F., Berger, S., and Drews, R.: Dynamic influence of pinning points on marine ice-sheet stability: a numerical study in Dronning Maud Land, East Antarctica, The Cryosphere, 10, 2623-2635, https://doi.org/10.5194/tc-10-2623-2016, 2016.

Fox Maule, C., Purucker, M. E., Olsen, N., and Mosegaard, K.: Heat Flux Anomalies in Antarctica Revealed by Satellite Magnetic Data, Science, 309, 464-467, https://doi.org/10.1126/science.1106888, 2005.

Fretwell, P., Pritchard, H. D., Vaughan, D. G., Bamber, J. L., Barrand, N. E., Bell, R., Bianchi, C., Bingham, R. G., Blankenship, D. D., Casassa, G., Catania, G., Callens, D., Conway, H., Cook, A. J., Corr, H. F. J., Damaske, D., Damm, V., Ferraccioli, F., Forsberg, R., Fujita, S., Gim, Y., Gogineni, P., Griggs, J. A., Hindmarsh, R. C. A., Holmlund, P., Holt, J. W., Jacobel, R. W., Jenkins, A., Jokat, W., Jordan, T., King, E. C., Kohler, J., Krabill, W., Riger-Kusk, M., Langley, K. A., Leitchenkov, G., Leuschen, C., Luyendyk, B. P., Matsuoka, K., Mouginot, J., Nitsche, F. O., Nogi, Y., Nost, O. A., Popov, S. V., Rignot, E., Rippin, D. M., Rivera, A., Roberts, J., Ross, N., Siegert, M. J., Smith, A. M., Steinhage, D., Studinger, M., Sun, B., Tinto, B. K., Welch, B. C., Wilson, D., Young, D. A., Xiangbin, C., and Zirizzotti, A.: Bedmap2: improved ice bed, surface and thickness datasets for Antarctica, The Cryosphere, 7, 375-393, https://doi.org/10.5194/tc-7-375-2013, 2013.

Fürst, J. J., Durand, G., Gillet-Chaulet, F., Tavard, L., Rankl, M., Braun, M., and Gagliardini, O.: The safety band of Antarctic ice shelves, Nat. Clim. Change, 6, 479-482, https://doi.org/10.1038/nclimate2912, 2016.

Gillet-Chaulet, F., Hindmarsh, R. C. A., Corr, H. F. J., King, E. C., and Jenkins, A.: In-situ quantification of ice rheology and direct measurement of the Raymond Effect at Summit, Greenland using a phase-sensitive radar, Geophys. Res. Lett., 38, L24503, https://doi.org/10.1029/2011GL049843, 2011.

Goodwin, A. H. and Vaughan, D. G.: A topographic origin for double-ridge features in visible imagery of ice divides in Antarctica, J. Glaciol., 41, 483-489, https://doi.org/10.3189/S0022143000034821, 1995.

Hawley, R. L., Courville, Z. R., Kehrl, L. M., Lutz, E. R., Osterberg, E. C., Overly, T. B., and Wong, G. J.: Recent accumulation variability in northwest Greenland from ground-penetrating radar and shallow cores along the Greenland Inland Traverse, J. Glaciol., 60, 375-382, https://doi.org/10.3189/2014JoG13J141, 2014

Herring, T. A., King, R. W., and McClusky, S. C.: Introduction to GAMIT/GLOBK, Massachusetts Institute of Technology, Cambridge, Massachusetts, 2010.

Herron, M. M. and Langway, C. C.: Firn Densification: An Empirical Model, J. Glaciol., 25, 373-385, https://doi.org/10.3189/S0022143000015239, 1980.

Hindmarsh, R. C. A., King, E. C., Mulvaney, R., Corr, H. F. J., Hiess, G., and Gillet-Chaulet, F.: Flow at ice-divide triple junctions: 2. Three-dimensional views of isochrone architecture from ice-penetrating radar surveys, J. Geophys. Res.-Earth, 116, F02024, https://doi.org/10.1029/2009JF001622, 2011.

Hvidberg, C. S.: Steady-state thermomechanical modelling of ice flow near the centre of large ice sheets with the finite-element technique, Ann. Glaciol., 23, 116-123, https://doi.org/10.3189/S026030550001332X, 1996.

Høydal, Ø. A.: A force-balance study of ice flow and basal conditions of Jutulstraumen, Antarctica, J. Glaciol., 42, 413-425, https://doi.org/10.3198/1996JoG42-142-413-425, 1996.

Jezek, K. C., Curlander, J. C., Carsey, F., Wales, C., and Barry, R.: RAMP AMM-1 SAR Image Mosaic of Antarctica, Version 1, NSIDC - National Snow and Ice Data Center, Boulder, Colorado USA, https://doi.org/10.5067/dhc0hdlzq184, 2002.

King, J. C.: Wind-borne redistribution of snow across an Antarctic ice rise, J. Geophys. Res., 109, D11104, https://doi.org/10.1029/2003JD004361, 2004.

Kingslake, J., Hindmarsh, R. C. A., Aðalgeirsdóttir, G., Conway, H., Corr, H. F. J., Gillet-Chaulet, F., Martín, C., King, E. C., Mulvaney, R., and Pritchard, H. D.: Full-depth englacial vertical ice sheet velocities measured using phasesensitive radar, J. Geophys. Res.-Ea. Surf., 119, 2604-2618, https://doi.org/10.1002/2014JF003275, 2014.

Kingslake, J., Martín, C., Arthern, R. J., Corr, H. F. J., and King, E. C.: Ice-flow reorganization in West Antarctica $2.5 \mathrm{kyr}$ ago dated using radar-derived englacial flow velocities: West Antarctic ice-flow reorganization, Geophys. Res. Lett., 43, 9103-9112, https://doi.org/10.1002/2016GL070278, 2016.

Kovacs, A., Gow, A. J. and Morey, R. M.: The in-situ dielectric constant of polar firn revisited, Cold Reg. Sci. Technol., 23, 245256, https://doi.org/10.1016/0165-232X(94)00016-Q, 1995.

Lenaerts, J. T., Brown, J., Van Den Broeke, M. R., Matsuoka, K., Drews, R., Callens, D., Philippe, M., Gorodetskaya, I. V., Van Meijgaard, E., Reijmer, C. H., Pattyn, F., and Van Lipzig, N. P.: High variability of climate and surface mass balance induced by Antarctic ice rises, J. Glaciol., 60, 1101-1110, https://doi.org/10.3189/2014JoG14J040, 2014.

Mackintosh, A. N., Verleyen, E., O'Brien, P. E., White, D. A., Jones, R. S., McKay, R., Dunbar, R., Gore, D. B., Fink, D., Post, A. L., Miura, H., Leventer, A., Goodwin, I., Hodgson, D. A., Lilly, K., Crosta, X., Golledge, N. R., Wagner, B., Berg, S., van Ommen, T., Zwartz, D., Roberts, S. J., Vyverman, W., and Masse, G.: Retreat history of the East Antarctic Ice Sheet since the Last Glacial Maximum, Quaternary Sci. Rev., 100, 10-30, https://doi.org/10.1016/j.quascirev.2013.07.024, 2014.

Martín, C., Gudmundsson, G. H., Pritchard, H. D., and Gagliardini, O.: On the effects of anisotropic rheology on ice flow, internal structure, and the age-depth relationship at ice divides, J. Geophys. Res., 114, F04001, https://doi.org/10.1029/2008JF001204, 2009a.

Martín, C., Hindmarsh, R. C. A., and Navarro, F. J.: On the effects of divide migration, along-ridge flow, and basal sliding on isochrones near an ice divide, J. Geophys. Res., 114, F02006, https://doi.org/10.1029/2008JF001025, 2009b.

Matsuoka, K., Pattyn, F., Callens, D., and Conway, H.: Radar characterization of the basal interface across the grounding zone of an ice-rise promontory in East Antarctica, Ann. Glaciol., 53, 29-34, https://doi.org/10.3189/2012AoG60A106, 2012a.

Matsuoka, K., Power, D., Fujita, S., and Raymond, C. F.: Rapid development of anisotropic ice-crystal-alignment fabrics inferred from englacial radar polarimetry, central West Antarctica, J. Geophys. Res., 117, F03029, https://doi.org/10.1029/2012JF002440, $2012 b$. 
Matsuoka, K., Hindmarsh, R. C. A., Moholdt, G., Bentley, M. J., Pritchard, H. D., Brown, J., Conway, H., Drews, R., Durand, G., Goldberg, D., Hattermann, T., Kingslake, J., Lenaerts, J. T. M., Martín, C., Mulvaney, R., Nicholls, K. W., Pattyn, F., Ross, N., Scambos, T., and Whitehouse, P. L.: Antarctic ice rises and rumples: Their properties and significance for icesheet dynamics and evolution, Earth-Sci. Rev., 150, 724-745, https://doi.org/10.1016/j.earscirev.2015.09.004, 2015.

Moholdt, G. and Matsuoka, K.: Inventory of Antarctic ice rises and rumples (version 1), Norwegian Polar Institute, Troms $\emptyset$, Norway, https://doi.org/10.21334/npolar.2015.9174e644, 2015.

Mulvaney, R., Oerter, H., Peel, D. A., Graf, W., Arrowsmith, C., Pasteur, E. C., Knight, B., Littot, G. C., and Miners, W. D.: 1000 year ice-core records from Berkner Island, Antarctica, Ann. Glaciol., 35, 45-51, https://doi.org/10.3189/172756402781817176, 2002.

Mulvaney, R., Triest, J., and Alemany, O.: The James Ross Island and the Fletcher Promontory icecore drilling projects, Ann. Glaciol., 55, 179-188, https://doi.org/10.3189/2014AoG68A044, 2014.

Nereson, N. A. and Raymond, C. F.: The elevation history of ice streams and the spatial accumulation pattern along the Siple Coast of West Antarctica inferred from ground-based radar data from three inter-ice-stream ridges, J. Glaciol., 47, 303-313, https://doi.org/10.3189/172756501781832197, 2001.

Nereson, N. A. and Waddington, E. D.: Isochrones and isotherms beneath migrating ice divides, J. Glaciol., 48, 95-108, https://doi.org/10.3189/172756502781831647, 2002.

Nereson, N. A., Raymond, C. F., Waddington, E. D., and Jacobel, R. W.: Migration of the Siple Dome ice divide, West Antarctica, J. Glaciol., 44, 643-652, https://doi.org/10.1017/S0022143000002148, 1998.

Neumann, T. A., Conway, H., Price, S. F., Waddington, E. D., Catania, G. A., and Morse, D. L.: Holocene accumulation and ice sheet dynamics in central West Antarctica, J. Geophys. Res.-Earth, 113, F02018, https://doi.org/10.1029/2007JF000764, 2008.
Raymond, C. F.: Deformation in the Vicinity of Ice Divides, J. Glaciol., 29, 357-373, https://doi.org/10.3189/S0022143000030288, 1983.

Reeh, N.: A flow-line model for calculating the surface profile and the velocity, strain-rate, and stress fields in an ice sheet, J. Glaciol., 34, 46-55, https://doi.org/10.3189/S0022143000009059, 1988.

Richardson, C., Aarholt, E., Hamran, S.-E., Holmlund, P., and Isaksson, E.: Spatial distribution of snow in western Dronning Maud Land, East Antarctica, mapped by a ground-based snow radar, J. Geophys. Res.-Sol. Ea., 102, 20343-20353, https://doi.org/10.1029/97JB01441, 1997.

Rignot, E. and Kanagaratnam, P.: Changes in the Velocity Structure of the Greenland Ice Sheet, Science, 311, 986-990, https://doi.org/10.1126/science.1121381, 2006.

Rignot, E., Mouginot, J., and Scheuchl, B.: Ice Flow of the Antarctic Ice Sheet, Science, 333, 1427-1430, https://doi.org/10.1126/science.1208336, 2011.

Siegert, M., Ross, N., Corr, H., Kingslake, J., and Hindmarsh, R.: Late Holocene ice-flow reconfiguration in the Weddell Sea sector of West Antarctica, Quaternary Sci. Rev., 78, 98-107, https://doi.org/10.1016/j.quascirev.2013.08.003, 2013.

Vaughan, D. G., Corr, H. F. J., Doake, C. S. M., and Waddington, E. D.: Distortion of isochronous layers in ice revealed by ground-penetrating radar, Nature, 398, 323-326, https://doi.org/10.1038/18653, 1999.

Vega, C. P., Schlosser, E., Divine, D. V., Kohler, J., Martma, T., Eichler, A., Schwikowski, M., and Isaksson, E.: Surface mass balance and water stable isotopes derived from firn cores on three ice rises, Fimbul Ice Shelf, Antarctica, The Cryosphere, 10, 2763-2777, https://doi.org/10.5194/tc-10-2763-2016, 2016.

Waddington, E. D., Neumann, T. A., Koutnik, M. R., Marshall, H.P., and Morse, D. L.: Inference of accumulation-rate patterns from deep layers in glaciers and ice sheets, J. Glaciol., 53, 694 712, https://doi.org/10.3189/002214307784409351, 2007.

Zwally, H. J. and Giovinetto, M. B.: Overview and Assessment of Antarctic Ice-Sheet Mass Balance Estimates: 1992-2009, Surv. Geophys., 32, 351-376, https://doi.org/10.1007/s10712011-9123-5, 2011. 